\title{
Study on Countermeasures of improving public health emergency management system in Liaoning Province Based on epidemic control survey data
}

\author{
Sun Ying ${ }^{1}$ \\ ${ }^{1}$ Institute of governance Party school of Liaoning provincial Party committee, Shenyang, P.R. China, 110161
}

\begin{abstract}
In the current round of prevention and control of cowid-19, Liaoning Province closely combines the current new situation, new changes and new characteristics, improves the normal prevention and control mechanism of timely discovery, rapid disposal, precise control and effective disposal, ensures that the management measures are effective and the work is in place, so as to create a healthy environment, maintain social stability and protect people's health. However, at the same time, through the statistics of the proportion of technical personnel and management personnel, the proportion of professional personnel, the number of disease control personnel per 10000 people and other data, we found that there are obvious shortcomings in the public health emergency management system of our province. Therefore, we should seize the opportunity, sum up the experience, draw lessons, pay close attention to the shortcomings, plug the loopholes, develop the advantages and avoid the disadvantages, and comprehensively improve the ability to deal with major public health emergencies.
\end{abstract}

\section{Introduction}

Since the outbreak of COVID-19, ensure the safety and health of the people is a major task for our party in governing the country. We should improve the system and mechanism of major epidemic prevention and control, and improve the national public health emergency management system[1]. It can be said that the soundness of the public health system can best reflect the modernization of a regional health service system. The public health system of our province has successfully dealt with many public health emergencies, such as SARS, avian influenza, hand foot mouth disease, influenza A (H1N1), human infection with H7N9 avian influenza, infant milk powder. It has been awarded "national heroic collective for earthquake relief" by the Central Committee of the Communist Party of China, the State Council and the Central Military Commission. The Ministry of health and the Ministry of personnel of the people's Republic of China have awarded "national health system first prize for fighting SARS" It has played a positive role in disease prevention, emergency response and public health information capacity building.

\section{Current situation and achievements of public health emergency management system in our province}

In June 2018, Liaoning Province issued the optimization and integration plan for public welfare institutions directly under the provincial government, reorganizing and integrating provincial and municipal CDC and health supervision departments. After the integration, Liaoning Province retained provincial CDC, and provincial health supervision was integrated into provincial health service center, which is a public institution affiliated to provincial health department. The institution level is county level, and the CDC and health supervision institutes below the provincial level are integrated. Based on the analysis of relevant documents published by Liaoning Province and its subordinate cities, on the one hand, the reform involves directly affiliated units of health and family planning, civil affairs, safety supervision and other departments. After adjustment and optimization, the number of public institutions is significantly reduced and the functions are more unified, which solves the disadvantages of excessive number, overlapping functions and cumbersome management of public institutions affiliated to administrative departments, and provides a reference for establishing a large-scale health and safety supervision system. It has played a great role in promoting the transformation from disease treatment as the center to people's health as the center, preventing and controlling major diseases, and providing people with all-round and full cycle health services.

In this new situation, Liaoning public health system also has a new development. On July 25, 2020, Liaoning Provincial Health Supervision Center was unveiled. Under the new situation of normalization of epidemic prevention and control, the independent establishment of health supervision institutions in Liaoning Province is an 
important decision made by Liaoning provincial government to comply with the requirements of national governance system and governance capacity modernization era, which reflects the full affirmation of Liaoning provincial government to health supervision work and the high attention to the construction of health supervision system[2]. In August, Liaoning was approved four national clinical research center sub centers, which indicates that the construction of clinical center system in our province has made important progress and will drive the clinical research in our province to a higher level of development. It is of great significance for Liaoning Province to comprehensively deepen the reform of medical and health system, further reform and improve the public health system, and promote the development of health undertakings.

On the other hand, we should also see that the major adjustment of the existing public health service system in our province involves a wide range of interests, and is not compatible with the current economic and social development situation in China. In the response of COVID-19, it also exposed some shortcomings and problems.

\section{Problems and causes of public health emergency management system in our province}

\subsection{Public health recognition is not high, "prospective governance" as a normal thinking needs to be strengthened}

In the current public health reform, we often focus on medical and health services, ignore the construction of preventive epidemic prevention system, and adopt the investment mode of "fire fighting in the middle, more and more vigorous"[3], which leads to a sharp increase in the number of patients and health investment, which not only aggravates the occurrence and development of systemic risk, but also has extremely high cost of prevention and control and governance. In contrast, the recognition of public health from all walks of life is not high, and there is no insurmountable red line of public health. In addition, the return cycle of public health services is relatively long, so it is difficult for the public to find its value and importance. Moreover, the characteristics of "the better the work is done, the less attention it is paid" also lead to the difficulty of rigid establishment of the normal thinking of "forward-looking governance".

\subsection{The disjunction of "medical treatment" and "prevention" is prominent, the position of public health system right and responsibility needs to be clarified}

In the public health system, the disease control system is gradually marginalized, which lags behind the overall progress of medical reform and the modernization process of the national overall governance system and governance capacity. In addition, there is a long-term lack of a public health law with clear functions, responsibilities and powers in the field of public health. The existing laws and regulations, such as the law on the prevention and control of infectious diseases, the law on emergency response, the law on the protection of wild animals, and the emergency regulations for public health emergencies, are difficult to meet the requirements of practical work. Although "prevention first, combination of prevention and control, gateway moving forward, promotion of resource sinking" proposed in "healthy China 2030" provides ideas for the overall construction of China's public health system, there is no special master plan and top-level design at present. Due to the fragmentation, governments at all levels pay different attention to the overall planning of public health resources, system construction, condition guarantee and other work within their jurisdiction, and the practical results are also different. This also leads to the serious tendency of "emphasizing medicine over health" in public hospitals, and the poor foundation, weak foundation and low capacity of public health service institutions. This is also reflected in the relevant statistical data of business coverage of disease control system in our province (as shown in Table 1).

TableI. Business coverage of disease control institutions in the province in 2018

\begin{tabular}{|c|l|c|c|c|c|}
\hline $\begin{array}{c}\text { Serial } \\
\text { number }\end{array}$ & $\begin{array}{l}\text { Specific } \\
\text { business }\end{array}$ & $\begin{array}{c}\text { Development } \\
\text { number }\end{array}$ & $\begin{array}{c}\text { Provincial } \\
\text { development rate (\%) }\end{array}$ & $\begin{array}{c}\text { City } \\
\text { development rate (\%) }\end{array}$ & $\begin{array}{c}\text { Development rate at } \\
\text { county and district level } \\
\text { (\%) }\end{array}$ \\
\hline $\mathbf{1}$ & $\begin{array}{l}\text { Health emergency } \\
\text { work }\end{array}$ & 115 & 100 & 100 & 99.01 \\
\hline $\mathbf{2}$ & Planned immunization & 115 & 100 & 100 & 100 \\
\hline $\mathbf{3}$ & $\begin{array}{l}\text { Infectious disease } \\
\text { work }\end{array}$ & 116 & 100 & 100 & 100 \\
\hline $\mathbf{4}$ & STD/ AIDS work & 116 & 100 & 50 & 48.51 \\
\hline $\mathbf{5}$ & Tuberculosis work & 57 & 100 & 92.86 & 92.08 \\
\hline $\mathbf{6}$ & $\begin{array}{l}\text { Work on endemic } \\
\text { diseases }\end{array}$ & 107 & 100 & 100 & 97.03 \\
\hline $\mathbf{7}$ & Chronic NCD work & 113 & 100 & 92.86 & 47.52 \\
\hline $\mathbf{8}$ & $\begin{array}{c}\text { Nutrition and food } \\
\text { hygiene }\end{array}$ & 62 & 100 & 100 & 75.25 \\
\hline $\mathbf{9}$ & $\begin{array}{c}\text { Enyironmental } \\
\text { sanitation work }\end{array}$ & 91 & 100 & 100 & 42.57 \\
\hline $\mathbf{1 0}$ & $\begin{array}{c}\text { Radiological health } \\
\text { work }\end{array}$ & 58 & 100 & 100 & 83.17 \\
\hline $\mathbf{1 1}$ & School health work & 99 & 100 & 92.86 & 92.08 \\
\hline $\mathbf{1 2}$ & Laboratory testing & 107 & 100 & & \\
\hline
\end{tabular}




\subsection{The public health system is relatively weak, and the support of people and property needs to be strengthened}

The lag and delay of reform inevitably make the functions of public health related institutions in swing. There are some phenomena, such as unclear trend of institutions, sharp decrease of funds, compressed establishment, loss of personnel, and even merger of institutions, which make some problems in the construction of public health service system in our province. For example, the allocation of high-quality resources is not balanced, showing an inverted pyramid structure as a whole; the health care force at the grass-roots level is relatively weak, and it is difficult to implement the hierarchical diagnosis and treatment system; The public health team is unstable and lack of attraction. According to the survey on the staff of disease control institutions at all levels in April 2020, the total number of CDCs in Liaoning Province in 2018 is 7382 , with $0.1415 \%$ CDCs per 10000 people, 2720 people $(44.1 \%)$ were lack of professionalism and low level of talents in the public health team (Table 2). 2152 people (34.89\%) had intermediate professional titles and 1618 people $(26.23 \%)$ had junior professional titles.

TABLE2. Professional composition of Liaoning provincial CDC personnel in 2018

\begin{tabular}{|l|l|l|l|}
\hline $\begin{array}{l}\text { Serial } \\
\text { number }\end{array}$ & Professional name & $\begin{array}{l}\text { Number of } \\
\text { people }\end{array}$ & $\begin{array}{l}\text { Proportion of } \\
\text { total investment } \\
\text { (\%) }\end{array}$ \\
\hline 1 & $\begin{array}{l}\text { Preventive } \\
\text { medicine }\end{array}$ & 1605 & 26.02 \\
\hline 2 & Clinical medicine & 1046 & 16.96 \\
\hline 3 & Nursing major & 368 & 5.97 \\
\hline 4 & Testing major & 1001 & 16.23 \\
\hline 5 & Other majors & 1856 & 30.09 \\
\hline
\end{tabular}

The public has no basic trust in general practitioners and grassroots health care forces, and the community police and doctors are obviously insufficient, For example, in 2018, the ratio of professional and technical personnel to management personnel in provincial CDC was 21.18:1, the ratio of professional and technical personnel to management personnel in municipal CDC was $8.24: 1$, and the ratio of professional and technical personnel to management personnel in County CDC was 4.54:1. The large-scale financial investment in public health system at all levels has not yet been transformed into institutional arrangements, and the source of funds is single, the financial budget has declined from time to time, the imbalance of public health investment among regions and other factors directly affect the effective performance of public health functions.

\subsection{The sensitivity of health risk is not enough, and the responsiveness of public health emergencies needs to be improved}

According to the current working mechanism and process, public health personnel are usually likely to intervene in the investigation after the clinicians report the situation of infectious diseases. The lagging action of prevention and control of infectious diseases is prominent, and it is difficult to adapt to the overall and rapid growth of public health needs. When new infectious diseases appear, the weak emergency response ability of public health emergencies is still a prominent weakness. With the acceleration of China's aging society, chronic diseases appear "blowout" state, but it has not yet formed an effective public health management system to deal with chronic diseases[4]. In addition, although medical institutions have developed health emergency management system, there are still some problems, such as nonstandard department isolation construction, inadequate personnel and facilities allocation, untimely emergency response speed, and imperfect symptom monitoring information sharing platform. For example, in terms of inspection ability, there are 349 items at the provincial level, 387 items below the national standard; 226 items at the municipal level, 387 items below the national standard; 55 items at the district and county level, 118 items below the national standard, which will affect the timely response and effective response to public health emergencies.

\subsection{The response linkage mechanism is not perfect, and the public health emergency management ability needs to be strengthened}

Although the basic institutional framework of "four beams and eight pillars" of public health system has been established, the public health management system and operation mechanism are not perfect, and the contradiction between fragmentation of management and decentralization of resources is still quite prominent. In novel coronavirus pneumonia outbreak, there were no major epidemic prevention and control mechanisms in all provinces, there were barriers in information interconnection and sharing, and there were still some problems such as poor information communication, inaccurate information and inadequate material preparation among relevant departments, resulting in delays in prevention and control. For example, due to the limited financial investment of governments at all levels in response to public health emergencies, epidemiological investigation and hospital infection control, hospitals will try to reduce the inventory investment of medical protective equipment, resulting in insufficient reserves of medical protective materials. In this epidemic prevention and control, the shortage of medical protection materials is the biggest weak link, and also the biggest weakness of public health and safety protection management.

\subsection{The problem of information "isolated island" is prominent, and the information construction of public health system needs to be strengthened}

In the current public health system, medical management organs, medical institutions and public health service institutions respectively assume different functions, and establish internal data collection and management 
information platforms respectively. However, there is no interconnection between the platforms, lack of unified standards, and emergency decision-making can not be applied. For example, the CDC at all levels involved in disease monitoring, vaccination, health emergency management, chronic disease prevention and control, five major health work, all failed to establish a complete topdown or bottom-up information system. In addition, the basic information system for National Health established in various regions and the information system set up by disease control institutions are separated and promoted in basic information collection, entry, standard use and management departments, and cannot be carried out in an integrated way. Moreover, a unified and efficient public health information platform has not been built, which leads to the information "chimney" and "island", which leads to many works that cannot be effectively connected. In addition, the data collection methods of each platform are not uniform, the statistical methods are backward, and the data collection and management system of epidemic situation are too much flawed, which seriously restricts the comprehensive management ability of public health emergencies.

\subsection{The awareness of active health is insufficient, and the public health literacy and emergency literacy need to be improved}

Health literacy refers to the ability of individuals to obtain and understand health information, and use it to maintain and promote their own health. Some data show that the health literacy level of Chinese residents is less than $20 \%$. Once a public health emergency occurs, it is easy to panic and do not know how to face it scientifically. At the same time, people from all walks of life do not understand and pay enough attention to the policy of putting prevention first, and the problem of "paying more attention to medical treatment than prevention" is widespread. The understanding and implementation of "integrating health into all policies" vary greatly among various departments, and few departments really implement the policy. They do not pay enough attention to the public health resource planning, system construction, security system and other work within their jurisdiction. It has seriously affected the implementation of the policy of putting prevention first.

\section{Suggestions on improving the public health emergency management system in our province}

\subsection{Based on the overall national security, we should re position the construction of the public health emergency management system in our province}

First, make it clear that people's security is the core of national security. Public health is closely related to all aspects of society, and it is the glue of all links. Public health plays an important role in protecting public security, maintaining social stability, promoting economic construction and social development by effectively resisting health risks, avoiding and reducing disease damage. People's safety is the cornerstone of national security. In the prevention and control of epidemic situation, we must put people's safety and health in the first place. Second, it is clear that public health security is the cornerstone of social security, and disease prevention and control is the core of public health security. The "opinions on the implementation of healthy China action" and "healthy China action (2019-2030)" issued by the State Council in July 2019 emphasize adhering to the peoplecentered healthy development idea, firmly establishing the concept of " big health system and big health", and adhering to the principle of prevention first and combination of prevention and treatment. Only by building a strong public health system, improving the early warning response mechanism, comprehensively improving the ability of prevention, control and treatment, weaving a dense protective net and building a solid separation wall, can effectively provide a strong guarantee for the maintenance of people's health[5].

\subsection{Clear definition of public health responsibility and right system}

First, adhere to the top-level design of the combination of "medicine" and "health". Strengthen the top-level design of "big health system and big health" public health management system, adapt to the requirements of the whole life cycle health management services, re position the government's public health responsibilities and the responsibilities of professional public health institutions, general hospitals and specialized hospitals, primary medical and health institutions, and reconstruct the professional public health organization network based on the principle of "separation of public welfare and profitability". We should integrate chronic diseases into the public health management framework, improve the public health management system with complementary functions, close cooperation and clear rights and responsibilities, realize the combination of prevention and treatment, and promote, guide and evaluate the implementation of "integrating health into all policies" by relevant departments. Second, strengthen the legal protection in the field of public health. Focusing on improving the pertinence, rationality and operability of legal regulation, especially the binding, strengthening the law enforcement supervision and administrative supervision in health-related fields, seriously evaluating the modification and improvement of laws and regulations are the only way to promote the prevention and control of epidemic diseases and the disposal of public health emergencies in accordance with the law. Only by making public health operate in a standard way, can it stand at a high level of capacity and play a role of forward-looking management of health risk in complex and changeable environment. 


\subsection{Strengthen the defense line of public health and promote the overall capacity of public health system in depth}

First, promote the overall upgrading of disease control system, medical system and scientific research system in the public health system. Public health management is highly professional, but it is far beyond the scope of pure medicine. In addition to medical and scientific research system, it is widely connected with several social governance branch systems, such as public management, emergency support, culture and education, sports, public opinion publicity, street community, environmental sanitation and urban construction. Therefore, the overall capacity improvement of public health system is a systematic work. Secondly, we should establish a normalized investment mechanism for talents, funds and policies. We will promote the efficient coordination and seamless connection between public health services and medical services, improve the working mechanism of combination of prevention and control, joint prevention and control, and mass prevention and treatment, and accelerate the exploration and establishment of a new disease prevention and control system. We should improve the staffing, improve the talent introduction and training mechanism, strengthen the performance evaluation and incentive and personnel post management. Make continuous and normalized investment in public health, so as to effectively enhance the "social visibility" of public health services.

\subsection{Stick to the duty of "scout" for Disease Control and improve the early warning system of public health emergencies}

First of all, enhance the ability of early monitoring and early warning. This is an important link in the effective response to public health emergencies, and it is an important move to improve the public health system. In the aspect of early monitoring and early warning, CDC should have clear rights and responsibilities, integrate administrative management and technical management, mobilize various resources, and implement technical measures quickly and efficiently. It is the core department in the prevention and control of infectious diseases and the emergency response of public health emergencies, and plays a decision-making role to ensure its authority and effectiveness in guiding medical and health and other institutions. This is not only conducive to early monitoring and early warning, but also conducive to the upper and lower linkage, horizontal collaboration, play the overall effectiveness of epidemic prevention and control. Secondly, we should improve the epidemic monitoring and early warning mechanism. The requirements and contents of early warning are much higher than and more than those of direct network reporting, including monitoring of infectious diseases, risk analysis and assessment, and difficult information release. The detection, evaluation and information release of suspicious cases, occurrence and development of cluster infection, clarify the specific division of functions, mutual relationship and prevention and control tasks, strengthen the tracking detection, evaluation and release of risk factors and development of epidemic situation, and timely remind the public to prepare, strengthen prevention and control, and avoid the spread of epidemic situation.

\subsection{Improve the operation mechanism of Public Health Emergencies Based on the overall effectiveness of prevention and control}

First, pay attention to the overall effectiveness of prevention and control. Focusing on the objectives of a series of public health sub-systems, such as the prevention and control of emerging infectious diseases and the emergency response of public health emergencies, it is the key to consolidate the responsibilities of all parties and improve the routine execution of the public health system. We should strengthen the joint defense and control mechanism, which is a mode of multi department efficient coordination, realize the combination of peacetime and wartime, and transform it into a conventional way of "healthy China" construction. Second, build a complete and relatively independent public health emergency system. Public health emergency response covers many links, such as risk communication, health education, medical detection and clinical diagnosis, home isolation guidance, medical observation, treatment of mild patients, severe rescue, hospice care and discharge follow-up, etc. It is necessary to overcome the disadvantages of fragmentation and discontinuity to the greatest extent. It is necessary to straighten out the relationship between the Commission of health and the center for Disease Control and Prevention, improve the governance level of local governments, plan ahead, lay out prevention, and respond to any future outbreak with more efficient emergency mechanism and more solid emergency plan. At the same time, we should formulate a more detailed and operational emergency plan for local public health emergencies, follow the bottom-line thinking, imagine the situation bad enough, prepare for the worst and make the best efforts.

\subsection{Promote the overall construction of public health information platform based on information interconnection}

First, establish a public health information system that meets the requirements of "symptom monitoring". Through and integrating the functions of existing infectious disease reports, infection in medical institutions, use of drug-resistant bacteria and antimicrobial drugs, as well as monitoring system functions of drugs, vaccines, food and laboratory biological safety, timely discover information of great significance for early warning of epidemic occurrence and epidemic. We will improve the monitoring and early warning system of infectious diseases in all kinds of medical institutions and disease control institutions at all levels, and improve the multichannel epidemic monitoring and rapid response information platform such as network direct report, public opinion monitoring, medical and health personnel report, scientific research findings report, etc. Secondly, strengthen the integration, mining analysis and evaluation 
of big data. We will improve the risk prediction and tracking system of public health emergencies, share the information of major epidemic risk monitoring and early warning, and make efforts to realize early detection, early reporting and early disposal of public health emergencies. We should improve the public health information release system, improve the corresponding information release system rules, and improve the authority of the information release system.

\subsection{Build a new pattern of public health service supply based on the concept of national health}

First, improve the continuous health service system. Whether it is the prevention and control of slow disease, the prevention and control of acute or new infectious diseases, we need to promote the transformation from environmental health management to comprehensive social health management, comprehensively improve the living environment, advocate civilized, healthy, green and environmental protection lifestyle, promote the integration of health into all policies, and push the party committees and governments at all levels to put patriotic health work on an important agenda. Secondly, the scientificity of public health policy should be improved. Public health group service involves many policy issues, which need to be determined according to the threat degree of disease to the population and the economic and social development conditions. The comprehensive factors such as the development of economic conditions, humanistic values and the acceptability of the public should also be considered.

\section{5 conclusion}

Public health governance aims to safeguard human health, focusing on preventing and responding to various potential public health threats, such as infectious diseases, air pollution, nuclear and biochemical events. This requires us to deeply reflect on the shortcomings of public health governance, and then orderly promote the process of modernization of public health governance, and enhance the overall capacity of public health governance in China. In the process of perfecting public health organization and system, we should follow the particularity and regularity of public health service, avoid all kinds of possible misunderstandings, and learn from foreign experience and lessons.

\section{References}

1. Liu Xiaolan. Thinking of public health emergency system based on big data [J]. China health standard management, 2021,12 (05): 3-6J. Clerk Maxwell, A Treatise on Electricity and Magnetism, 3rd ed., vol. 2. Oxford: Clarendon, 1892, pp.68-73.

2. Zhu Hui, Lu Jiehua. Support conditions and practice path of public health emergency linkage system with Chinese characteristics [J]. Journal of Shanghai University of administration, 2021,22 (02): 4-14.
3. Wang Jun, Zhao Lintao, Xu Kaiwei, Gao Hui. Challenges and ideas of medical security and public health emergency management system under the background of major epidemic [J]. Journal of Henan University (Medical Edition), 2021,40 (01): 58-61.

4. Gu Xin, Ning Jing. Toward specialization and de administration: the way of governance reform of China's disease prevention and control system [J]. Learning and exploration, 2021 (01): 95-102.

5. Gao Ling. Accelerating the construction of public health system [J]. Shanghai People's Congress monthly, 2020 (12): 27. 